\title{
POST-STROKE PSYCHIATRIC DISORDERS: AN OVERVIEW ON ITS SCREENING AND MANAGEMENT
}

\author{
KEERTHANA CHANDRASEKAR, NAKKA GAUTAM SAI, PRINCY SABU JOHN, SRUTHI NINAN, RAJA D, \\ PONNUSANKAR $S^{*}$
}

\begin{abstract}
Department of Pharmacy Practice, JSS College of Pharmacy, Udhagamandalam, The Nilgiris, Tamil Nadu. JSS Academy of Higher Education and Research, Mysuru, Karnataka, India. Email: ponnusankarsivas@gmail.com
\end{abstract}

Received: 19 March 2018, Revised and Accepted: 21 August 2018

\begin{abstract}
Stroke is the third leading cause of death. Stroke occurs when an insufficient amount of blood is supplied to the brain due to a thrombus or an emboli leading to permanent tissue damage. Lesions in the brain can lead to psychiatric complications. The prevalence of psychiatric complications after stroke is very common. Psychiatric complications such as depression, anxiety, apathy, pseudobulbar effects (laughing and crying), mania, psychosis, and bipolar disorders are seen after stroke. In this review, various psychiatric disorders are reported among post-stroke survivors in which depression and anxiety are common. Consequently, apathy, pseudobulbar effects, catastrophic reactions, psychosis, bipolar disorder, and mania are also observed after stroke. Therefore, early detection and management of psychiatric disorders prevent further complications and improve the quality of life in post-stroke patients.
\end{abstract}

Keywords: Post-stroke psychiatric disorder, Depression, Anxiety, Apathy, Catastrophic reactions, Mania.

(c) 2019 The Authors. Published by Innovare Academic Sciences Pvt Ltd. This is an open access article under the CC BY license (http://creativecommons. org/licenses/by/4. 0/) DOI: http://dx.doi.org/10.22159/ajpcr.2019.v12i1.26047

\section{INTRODUCTION}

Stroke is the third leading cause of death after cardiovascular diseases. Stroke occurs when an insufficient amount of blood is supplied to the brain due to a thrombus or an emboli leading to permanent tissue damage. Moreover, stroke lesions will lead to psychiatric complications such as depression, anxiety, apathy, pseudobulbar affects (laughing and crying), mania, psychosis, and bipolar disorders which were known for $>100$ years [1,2]. Post-stroke depression, a mood disorder is an important neuropsychiatric consequence of stroke [3]. Prevalence data on psychiatric complications include depression - 35\%, anxiety - $25 \%$, apathy $-20 \%$, pseudobulbar effects - $20 \%$, catastrophic reactions - $20 \%$, psychosis - rare, bipolar disorder - $<0.1 \%$, and mania - $<1 \%$ [4].

Post stroke depression being a psychiatric disorder affects patients, clinicians and as a whole the society due to physical, psychological, interpersonal and financial problems. Further by delaying the recovery and affecting quality of life it increases burden to care givers [1,5]. Aphasia, left hemisphere stroke, smoking, cognitive impairment, and stroke recurrence are the predictors of post-stroke depression [6]. Generalized anxiety disorder (GAD), panic disorder, social phobia, specific phobia, obsessive-compulsive disorder, and post-traumatic stress disorder can contribute to post-stroke anxiety [7]. Apathy is defined as loss of interest moreover; the negative effects of apathy include caretaker distress, reduced functional recovery, and loss of social independence [8]. Catastrophic reaction is a rare mood disorder manifested by a sudden explosion of strong emotions such as anxiety, crying, and agitation that occurs when a person cannot perform their daily activities which were possible before [1]. Spontaneous, unmanageable events of laughter or crying or both provoked by the presence or absence of a stimulus which actually did not lead the person to laugh or cry are known as pseudobulbar effects ordinarily coined in other terms as emotional liability and emotional incontinence [9]. Mania is manifested by elevated or irritable mood, increased interruption in language, thoughts, and contents [10]. Bipolar disorder is a severe mood disorder which leads to increased depression and mania among stroke survivors. Post-stroke psychosis is a neuropsychiatric disorder characterized by hallucination, psychomotor agitation, thought disorder, delusional beliefs, and euphoria [11].

A thorough literature review using PubMed, ScienceDirect, Biomed Central, PsychINFO, and PLOS databases and the articles from 1995 to 2017 in English are reviewed, using search words of stroke-associated psychiatric disorders - depression, anxiety, apathy and catastrophic reactions, screening, and pharmacological management. This review discusses on the aspects of screening and management of psychiatric disorders after stroke.

\section{POST-STROKE DEPRESSION}

The main symptoms of post-stroke depression are appetite disturbance, fatigue, insomnia, hopelessness, guilt, prolonged sadness, suicidal thoughts, anhedonia (grief), apathy, mood disorder, and cognitive impairment which are noted in elderly patients and also those with financial, family, and health-related stress at the time of stroke $[1,5,12,13]$. Female gender, decreased activities of daily life, lack of social support, history of previous stroke, and smoking are the risk factors for post-stroke depression $[14,15]$.

2.4 million of 5 million survivors after stroke had depression, among which half of them had major depression which was estimated by the American Heart Association [1]. Females are predicted to have early onset of post-stroke depression than males due to psychological and social stress leading to imbalance in psychological and physiological aspects $[15,16]$.

However, there are many rating scales to measure depression which include Hamilton depression rating scale, geriatric depression scale, beck depression inventory scale, functional independence measure (FIH), post-stroke depression rating scale, and barthel index are few to consider measuring the depression. Accordingly, some authors suggest that Diagnostic and Statistical Manual (DSM) of Mental Disorders, $4^{\text {th }}$ Edition, is the diagnostic criteria for post-stroke depression [17]. Few authors suggested Hamilton Depression Rating Scale, Geriatric Depression Scale, Beck Depression Inventory, Montgomery-Asberg 
Depression Rating Scale, and Zung Depression Scale for the depression scores [18]. Hamilton Rating Scale and Modified Barthel score were used in an outcome study of post-stroke depression rehabilitation study [19]. In an investigational test study, post-stroke Depression Rating Scale and Hamilton Depression Rating Scale were applied for the patients who were classified under DSM of Mental Disorders, Third Edition, Revised diagnostic criteria [20]. A study on Japanese patients used the National Institute of Health Stroke Scale for measuring the severity of depressive symptoms during the hospitalization period in addition to Japan Stroke Scale-D and FIH [21]. Other prospective study in South London stroke patients used Barthel Index $<15$, MiniMental State Examination (MMSE) $<24$, Abbreviated Mental Test $<8$, Frenchay Activities Index, and Hospital Anxiety And Depression Scale (HADS) [22]. A review in 2010 stated that the symptoms and severity were calculated using $\mathrm{SCID}^{2}$ (Structured Clinical Interview for DSM-IV) or $\mathrm{CIDI}^{3}$ (Composite International Diagnostic Interview for DSM-IV) by MMSE and applied to DSM-IV criteria ${ }^{2}$. Patient Health Questionnaire is considered and used as an updated tool for diagnosing post-stroke depression [23].

Pharmacological therapies such as selective serotonin reuptake inhibitor and tricyclic antidepressants are effective in the treatment of post-stroke depression, however, associated with a greater risk of stroke $(48 \%)[24,25]$. Nortriptyline is the drug of choice for treating post-stroke depression until unless there are no contraindications such as cardiac arrest, cardiac arrhythmia, or orthostatic hypotension. The following are some of the non-pharmacological therapies which will help to prevent the post-stroke depression.

- Self-management includes extended activities of daily life and improves the self-efficiency [26]. Rehabilitation, a target-oriented therapy, reduces the social impairment and hypothymia $[27,28]$. Cardiac rehabilitation mainly focuses on the preventive measures for transient ischemic stroke [29]. Psychological therapy helps in the prevention of the occurrence of post-stroke depression mostly in 5-HTTLPRR S allele carriers [30,31]. It includes cognitive therapy, problem-solving therapy, and motivational therapy. Cognitive therapy corrects the negative therapy and increases the daily activities, thereby facilitating problem-solving skills and cognitive restructuring skills to manage the ongoing tensions [32-35]. Problem-solving therapy reduces the mental disability and reduces the mortality $[36,37]$. Motivational therapy motivates medication adherence in patients with post-stroke depression [38].

- Verbal therapy includes literature therapy (expressive therapy) and story therapy (narrating a person's story) [39]. Non-verbal consists of music therapy and art therapy. Music therapy helps in improving emotional aspects of life [40]. Listening to music generates motions and emotions and thereby enhances the cognitive and emotions functions in patients [41,42]. 64.3\% of stroke patients in music therapy showed mood improvement [43]. It involves exercises using musical instruments which accelerate the motor function by producing a change in cortical plasticity and rapid plastic adaptation $[44,45]$. Art therapy forms a patient rapport with the therapist by free self-expression through painting or drawing [46].

- Community reintegration is the reorganization of physical, psychological, and social characteristics of the patient [47]. Physiotherapy involves the following three main therapies:

Physical exercise consists of voluntary bodily movement, acts by increasing the dopamine level, and helps to improve functional performance, thereby increasing the cardiorespiratory fitness and thus reducing the cardiovascular events [48-51].

Weight management uses the latest system $\mathrm{CHANGE}^{\mathrm{TM}}$ that motivates overweight survivors to reduce their weight up to $5 \%$ [52].

Yoga aids to improve the muscle strength, aerobic capacity, and plasticity and used as an adjuvant therapy in post-stroke depression $[53,54]$.

- Acupuncture therapy initiated in China is a process of restoring the neuroimaging activity of the brain region involved in the emotional activity processing and improves the depressive symptoms. It shows a high curative rate with no obvious side effects [55-58].

- Electroconvulsive therapy involves the passage of electric current through the brain with the help of anesthetic and muscle relaxant. It changes the pattern of blood flow and helps in the growth of new nerve cells [59].

- Transcranial stimulation targets the distributed brain network responsible for depression and delivers magnetic stimulation in short time. Transcranial direct current stimulation along with cognitive control therapy as a combination is used to treat the post-stroke depression, and it showed a response rate of $25 \%$ and is beneficial in chronic stroke patients [60-62].

\section{POST-STROKE ANXIETY}

Anxiety is a common disorder observed after stroke which is occurred due to lesions in the right hemisphere. The main risk factors of poststroke anxiety include post-stroke depression, pre-stroke anxiety or depression, coping, confidence, tiredness, and lack of sleep leading to decreased quality of life and physical disability [63]. Consequently, anxiety is more commonly seen in women and younger population [64]. The most common anxiety disorders seen in stroke patients includes GAD, panic disorder, social phobia, specific phobia, obsessive and compulsive disorder, and post-traumatic stress disorder [7].

Beck Anxiety Inventory Scale (BAI) consists of 21 items which mainly focus on symptoms such as fear of dying, scared, loss of balance/ wobbliness, and fearing the worst.

- 14 items which focus on somatic symptoms (trembling hands) and 7 items on reflect thoughts or emotions (fear of dying).

- Total score range is 0-63 (0-7 - minimal, 8-15 - mild, 16-25 moderate, and 26-63 - severe) [65].

Anxiety can be assessed using different scales such as HADS-A, Hamilton Anxiety Scale-A, BAI, Irritability Depression and Anxiety Scale, GAD2 questionnaire, post-traumatic diagnostic scale, and post-traumatic stress disorder checklist for a stressor. MMSE shows the association between post-stroke anxiety and cognitive impairment, whereas Victoria Stroop Dots Trial shows reduced cognition. Post-stroke anxiety and health-related quality of life are measured using 12-item Medical Outcomes Short Form Health Survey (SF-12). The Negative Affect Schedule and Behavioral Index Form found an association between trait negativity and behavioral reactions of denial with post-stroke anxiety [63]. Barthel Index is a tool which is used to measure the anxiety and depressive patient's dependency on activities of daily living although the low score implies that the patient requires someone to perform their usual activities [64].

Serotonin-norepinephrine reuptake inhibitors (SNRIs) are more superior over SSRIs because of its dual action (inhibiting) on serotonergic and adrenergic receptors. Treatment with duloxetine (SNRI) is more effective than citalopram and sertraline for anxiety symptoms such as decreased appetite, psychomotor retardation, and physical impairment. Zoplicone and zaleplon are the hypnotics used for treating insomnia in GAD and post-traumatic stress disorder [7].

The non-pharmacological treatment, slow-stroke back massage can reduce the pain levels, anxiety, and other physiological measures such as heart rate and blood pressure (systolic and diastolic) which yields for $10 \mathrm{~min}$ and is an effective treatment for older patients with strokerelated pain and anxiety [66].

Autogenic relaxation training is available in a self-help CD format; moreover it is advantageous and acceptable treatment for reducing anxiety in stroke survivors [67]. Sudarshan Kriya Yoga is beneficial, less costly and helps in reducing stress, anxiety, depression, substance abuse, post-traumatic stress disorders, and stress-related medical conditions; moreover, it maintains the balance of autonomic nervous system. This exercise helps in improving well-being, mood, attention, mental focus, and stress tolerance [68]. 


\section{POST-STROKE APATHY}

Apathy can be defined as a motivational disorder which is associated with a loss of motivation, concern, and lack of interest in oneself and social life leading to a reduced interaction with their own environment [8]. Older age, cognitive impairment, and functional decline are the risk factors for post-stroke apathy [69]. The main symptoms of post-stroke apathy are depression, cognitive impairment, and disability [70].

Types of apathy include classical, depressive, and combined. Classic or combined apathy is due to medium lesions and is seen mostly in men, whereas depressive apathy is seen more in women and is associated with small lesions. Common problems of stroke are apathy which can be manifested on the basis of poorer outcomes. Approximately 1 of 3 patients will develop apathy but is low in patients who have no previous history of cerebrovascular diseases, and there is no difference between ischemic and hemorrhagic stroke apathy rates [71]

The relation between apathy and cognitive impairment can be explained by two factors:

- Lack of adequate goal specified thinking and behavior can lead to loss of interest.

- Lesions in the brain areas affect the anterior cingulate circuit (memory and learning) leading to a lack of motivation, apathy, and cognitive impairment [70].

Screening for apathy is done on a regular basis using different tools such as the World Health Organization-5, Apathy Evaluation Scale, Beck Depression Inventory, and Chinese version of the Neuropsychiatry Intervention.

The pharmacological treatment suggests a daily dose of nefiracetam-900 mg given for 4 weeks or cilostazol for 6 months helps in reducing symptoms of apathy in post-stroke depression. The non- pharmacological treatment such as problem-solving therapy, motivational therapy, milieu therapy, and occupational therapy showed a significant reduction in apathy after stroke [72].

\section{POST-STROKE PSEUDOBULBAR EFFECTS}

Spontaneous, unmanageable events of laughter or crying or both provoked by the presence or absence of a stimulus which actually did not lead the person to laugh or cry are known as pseudobulbar effects ordinarily coined in other terms such as emotional labiality and emotional incontinence. The causes of pseudobulbar effects are schizophrenia, mania, depression, gestic or laughing epilepsy, Parkinson's disease, and Parkinson plus [9,73]. Pathogenesis of pseudobulbar effects is explained by three hypotheses as shown in Fig. 1.

The symptoms of pseudobulbar effects are a loss of emotional control such as laughing or crying, response to unwanted or non-specific stimulus, and lack of association with present mood state. Pathological laughing and crying scale is a diagnostic tool which measures the duration, degree of voluntary control, relationship to external events, inappropriateness in relation to current emotions, and extent of distress for laughing and crying.

The pharmacological treatment suggests tricyclic antidepressants (amitriptyline and nortriptyline), dopaminergic (levodopa), SSRIs (fluoxetine, citalopram, sertraline, and paroxetine), dextromethorphan, and quinidine. Selective serotonin reuptake inhibitors are preferred over tricyclic antidepressants (high chances of anticholinergic side effects) accordingly to be started within 1-3 days to treat serotonin deficits. Lamotrigine along with dextromethorphan $30 \mathrm{mg}$ or quinidine $30 \mathrm{mg}$ is effective in treating pseudobulbar effects. Psychosocial treatment such as cognitive behavioral therapy is found to be effective [73].

\section{POST-STROKE MANIA}

Mania represents elevated or irritable mood along with increased disturbance in language, thoughts, and contents ordinarily caused by

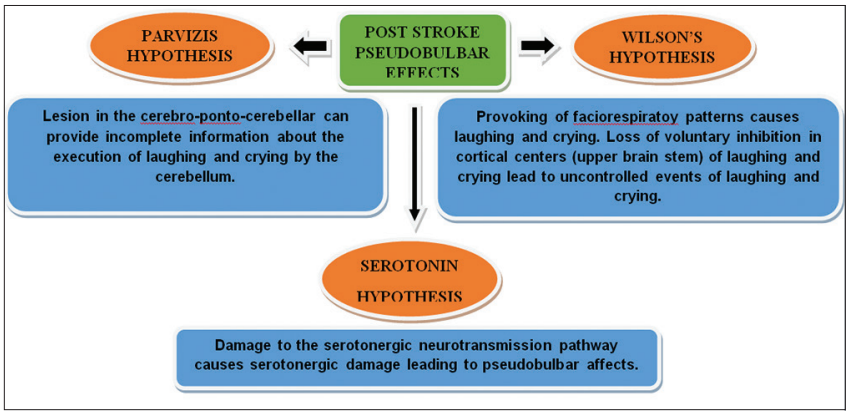

Fig. 1: Various pathogenesis of pseudobulbar effects

predisposing genetic factor, brain atrophy, and disruption in the right corticolimbic pathways. The main symptoms of mania are changes in speech, fight of ideas, lack of insight, and behavioral distress manifested by overactivity and social disinhibition [10]. Secondary mania symbolizes elevated or irritable mood caused by neurological, metabolic, or toxic disorders. The symptoms of secondary mania are hyperactivity, pressured speech and fight of ideas, reduced sleep, and lack of judging skills [74].

The pharmacological treatment suggests the use of mood stabilizers and typical and atypical antipsychotics. Moreover, lithium has favorable/ positive results, but its use is questionable in the case of cerebral lesions and atypical antipsychotics are ordinarily preferred because of minor side effects. Benzodiazepines may be used as supporting therapy for hyperactivity and lack of sleep. Anticonvulsants such as divalproex sodium are effective and well-tolerated choice of treatment in the elderly and in secondary mania [11].

\section{POST-STROKE CATASTROPHIC REACTIONS}

Catastrophic reaction is a rare mood disorder manifested by sudden explosion of strong emotions such as anxiety, crying, and agitation that occurs when a person cannot perform their daily activities which were possible before due to ganglial lesion and subcortical damage [75]. The symptoms of catastrophic reactions are expressive aphasia, destructive emotional explosion, anxiety, aggressiveness, and frustration [76].

\section{POST-STROKE BIPOLAR DISORDERS}

Bipolar disorder is a severe mood disorder which leads to increased depression and maniaamong stroke survivors consequently seen in adult compared to the elderly [11]. Majority of the studies report that mania followed by stroke is due to lesions at the right hemisphere and damage to the frontal-basal ganglia-thalamocortical circuits by subcortical vascular lesions $[77,78]$. The non-pharmacological treatment options for bipolar disorder are interpersonal therapy, cognitive therapy, family therapy, and psychoeducation. The pharmacological treatment for bipolar disorder includes lamotrigine and levetiracetam [79].

\section{POST-STROKE PSYCHOSIS}

Post-stroke psychosis is a neuropsychiatric disorder characterized by hallucination, psychomotor agitation, thought disorder, delusional beliefs, and euphoria [80]. The pathophysiology involved in post-stroke psychosis is a direct injury to the frontal lobes or disruption of normal frontal lobe functioning through damage to connections between the prefrontal cortices and subcortical structures causing impairment of motor functions [81]. A partial response is observed after giving olanzapine on both $2.5 \mathrm{mg}$ and $5 \mathrm{mg}$ evening doses, and mainly, sleep and anxiety were improved [82]. Quality of life and symptoms can be improved by three main factors such as combination therapy, lifestyle changes, and by priorly managing the risk factors of stroke which helps to reduce the cost burden on patients $[83,84]$.

Various psychiatric disorders were observed in post-stroke survivors in which depression and anxiety are common than apathy, pseudobulbar 
affects, catastrophic reactions, psychosis, bipolar disorder, and mania. Early recognition of post-stroke psychiatric disorders in patients helps to provide the appropriate management to minimize the risk and achieve a better quality of life. Different scales such as Hamilton Depression Rating Scale, Hospital Anxiety And Depression Rating Scale, MMSE, Post-Stroke Depression Rating Scale, Hamilton Depression Scale, and Barthel index are used for the screening of psychiatric disorders. Apart from general management, other non-pharmacological therapies are available which includes behavioral therapy, music therapy, literature therapy, and slow-stroke back massage therapy which are found to be beneficial and helped in reducing psychiatric problems associated with stroke.

\section{ACKNOWLEDGMENT}

The authors would like to thank Ms. Sini Satish B.Sc B.Ed, PGD HRM, and IELTS British council certified trainer for making necessary language correction to this paper.

\section{AUTHORS' CONTRIBUTIONS}

Keerthana Chandrasekar has provided the content, design, intellectual concept, data analysis, manuscript preparation, edition, and review along with the mentorship.

Nakka Gautam Sai has majorly involved in the literature search, data acquisition, and data analysis.

Princy Sabu John has majorly involved in the literature search, data acquisition, manuscript preparation, and manuscript editing.

Sruthi Ninan has provided the content, literature search, manuscript preparation, and manuscript editing.

D. Raja has provided the data analysis, manuscript editing, and manuscript review and guaranteed the article.

S. Ponnusankar has majorly helped in the intellectual concept, design, manuscript preparation, editing, and review and sincerely authored this article.

\section{CONFLICTS OF INTEREST}

The authors declare that there are no conflicts of interest regarding the publication of this article.

\section{REFERENCES}

1. Vani R. Neuropsychiatry of Stroke. $1^{\text {st }}$ ed. Washington, DC: Psychiatry; 2015 .

2. Robinson RG, Spalletta G. Poststroke depression: A review. Can J Psychiatry 2010;55:341-9.

3. Gall A. Post stroke depression. Hosp Med 2001;62:268-73.

4. Pierre T. Post-stroke Mania: The Behavioral and Cognitive Neurology of Stroke. $1^{\text {st }}$ ed. Cambridge: Cambridge University Press; 2007.

5. Primeau F. Post-stroke depression: A critical review of the literature. Can J Psychiatry 1988;33:757-65.

6. Shi Y, Xiang Y, Yang Y, Zhang N, Wang S, Ungvari GS, et al. Depression after minor stroke: Prevalence and predictors. J Psychosom Res 2015;79:143-7.

7. Campbell Burton CA, Holmes J, Murray J, Gillespie D, Lightbody CE, Watkins CL, et al. Interventions for treating anxiety after stroke. Cochrane Database Syst Rev 2011;12:CD008860.

8. Pedro L, Nuria AD. Poststroke Apathy. Rev Esp Geriatr Gerontol 2015;51:164-9.

9. Gupta A, Kedar M, Rajesh KR. Pathological laughter and crying. Delhi Psychiatry J 2007;10:25-30.

10. Santos CO, Caeiro L, Ferro JM, Figueira ML. Mania and stroke: A systematic review. Cerebrovasc Dis 2011;32:11-21.

11. Evans DL, Byerly MJ, Greer RA. Secondary mania: Diagnosis and treatment. J Clin Psychiatry 1995;56 Suppl 3:31-7.

12. Nakase T, Tobisawa M, Sasaki M, Suzuki A. Outstanding symptoms of post stroke depression during the acute phase of stroke. PLoS Med 2016;11:1-13.
13. McCarthy MJ, Sucharew HJ, Alwell K, Moomaw CJ, Woo D, Flaherty ML, et al. Age, subjective stress, and depression after ischemic stroke. J Behav Med 2016;39:55-64.

14. Jiang XG, Lin Y, Li YS. Correlative study on risk factors of depression among acute stroke patients. Eur Rev Med Pharmacol Sci 2014;18:1315-23.

15. Shi YZ, Xiang YT, Yang Y, Zhang N, Wang S, Ungvari GS, et al. Depression after minor stroke: Prevalence and predictors. J Psychosom Res 2015;79:143-7.

16. Zhang WN, Pan YH, Wang XY, Zhao Y. A prospective study of the incidence and correlated factors of post-stroke depression in China. PLoS One 2013;8:e78981.

17. Shi YZ, Xiang YT, Wu SL, Zhang N, Zhou J, Bai Y, et al. The relationship between frontal lobe lesions, course of post-stroke depression, and 1-year prognosis in patients with first-ever ischemic stroke. PLoS One 2014;9:e100456.

18. Hackett ML, Yapa C, Parag V, Anderson CS. Frequency of depression after stroke: A systematic review of observational studies. Stroke 2005;36:1330-40.

19. Loong CK, Kenneth NK, Paulin ST. Post-stroke depression: Outcome following rehabilitation. Aust N Z J Psychiatry 1995;29:609-14.

20. Gainotti G, Azzoni A, Razzano C, Lanzillotta M, Marra C, Gasparini F, et al. The post-stroke depression rating scale: A test specifically devised to investigate affective disorders of stroke patients. J Clin Exp Neuropsychol 1997;19:340-56.

21. Metoki N, Sugawara N, Hagii J, Saito S, Shiroto H, Tomita T, et al. Relationship between the lesion location of acute ischemic stroke and early depressive symptoms in Japanese patients. Ann Gen Psychiatry 2016;15:12.

22. Wolfe CD, Crichton SL, Heuschmann PU, McKevitt CJ, Toschke AM, Grieve AP, et al. Estimates of outcomes up to ten years after stroke: Analysis from the prospective south London stroke register. PLoS Med 2011;8:e1001033.

23. Gawronski DW, Reding MJ. Post-stroke depression: An update. Curr Atheroscler Rep 2001;3:307-12.

24. Youn JI, Sung KK, Song BK, Kim M, Lee S. Effects of electroacupuncture therapy on post-stroke depression in patients with different degrees of motor function impairments: A pilot study. J Phys Ther Sci 2013;25:725-8.

25. Alexopoulos GS, Wilkins VM, Marino P, Kanellopoulos D, Reding M, Sirey JA, et al. Ecosystem focused therapy in poststroke depression: A preliminary study. Int J Geriatr Psychiatry 2012;27:1053-60.

26. Parke HL, Epiphaniou E, Pearce G, Taylor SJ, Sheikh A, Griffiths CJ, et al. Self-management support interventions for stroke survivors: A Systematic meta-review. PLoS One 2015;10:e0131448.

27. Pustokhanova L, Morozova E. Cognitive impairment and hypothymia in post stroke patients. J Neurol Sci 2013;325:43-5.

28. López-Liria R, Vega-Ramírez FA, Rocamora-Pérez P, Aguilar-Parra JM, Padilla-Góngora D. Comparison of two post-stroke rehabilitation programs: A Follow-up study among primary versus specialized health care. PLoS One 2016;11:e0166242.

29. Lennon O, Blake C. Cardiac rehabilitation adapted to transient ischaemic attack and stroke (CRAFTS): A randomised controlled trial. BMC Neurol 2009;9:9.

30. Wichowicz HM, Puchalska L, Rybak-Korneluk AM, Gąsecki D, Wiśniewska A. Application of solution-focused brief therapy (SFBT) in individuals after stroke. Brain Inj 2017;31:1507-12.

31. Andersen G, Vestergaard K, Lauritzen L. Effective treatment of poststroke depression with the selective serotonin reuptake inhibitor citalopram. Stroke 1994;25:1099-104.

32. Jakobsen JC, Lindschou Hansen J, Storebø OJ, Simonsen E, Gluud C. The effects of cognitive therapy versus "treatment as usual" in patients with major depressive disorder. PLoS One 2011;6:e22890.

33. Thomas SA, Coates E, das Nair R, Lincoln NB, Cooper C, Palmer R, et al. Behavioural activation therapy for depression after stroke (BEADS): A study protocol for a feasibility randomised controlled pilot trial of a psychological intervention for post-stroke depression. Pilot Feasibility Stud 2016;2:45

34. Mitchell PH, Veith RC, Becker KJ, Buzaitis A, Cain KC, Fruin M, et al. Brief psychosocial-behavioral intervention with antidepressant reduces poststroke depression significantly more than usual care with antidepressant: Living well with stroke: Randomized, controlled trial. Stroke 2009;40:3073-8.

35. Kootker JA, Fasotti L, Rasquin SM, van Heugten CM, Geurts ACh. The effectiveness of an augmented cognitive behavioural intervention for post-stroke depression with or without anxiety (PSDA): The restore4Stroke-PSDA trial. BMC Neurol 2012;12:51. 
36. Alexopoulos GS, Raue PJ, Kiosses DN, Mackin RS, Kanellopoulos D, McCulloch C, et al. Problem-solving therapy and supportive therapy in older adults with major depression and executive dysfunction: Effect on disability. Arch Gen Psychiatry 2011;68:33-41.

37. Robinson RG, Jorge RE, Long J. Prevention of poststroke mortality using problem-solving therapy or escitalopram. Am J Geriatr Psychiatry 2017;25:512-9.

38. Barker-Collo S, Krishnamurthi R, Witt E, Feigin V, Jones A, McPherson $\mathrm{K}$, et al. Improving adherence to secondary stroke prevention strategies through motivational interviewing: Randomized controlled trial. Stroke 2015;46:3451-8.

39. Eum Y, Yim J. Literature and art therapy in post-stroke psychological disorders. Tohoku J Exp Med 2015;235:17-23.

40. Kim DS, Park YG, Choi JH, Im SH, Jung KJ, Cha YA, et al. Effects of music therapy on mood in stroke patients. Yonsei Med J 2011;52:977-81.

41. Altenmuller EO, Schlaug G. Neurologic music therapy: The beneficial effects of music making on neurorehabilitation. Acoust Sci Technol 2013;34:5-12.

42. Forsblom A, Laitinen S, Särkämö T, Tervaniemi M. Therapeutic role of music listening in stroke rehabilitation. Ann N Y Acad Sci 2009;1169:426-30

43. Jessica L, Arpan S, Donglin Y, Jessica R. Acute stroke, effect on mood, and music therapy: A non-pharmacological intervention. J Neurol 2017;88 Suppl 16:288

44. Amengual JL, Rojo N, Veciana de Las Heras M, Marco-Pallarés J, Grau-Sánchez J, Schneider S, et al. Sensorimotor plasticity after musicsupported therapy in chronic stroke patients revealed by transcranial magnetic stimulation. PLoS One 2013;8:e61883.

45. Schneider S, Schönle PW, Altenmüller E, Münte TF. Using musical instruments to improve motor skill recovery following a stroke. J Neurol 2007;254:1339-46.

46. Beesley K, White JH, Alston MK, Sweetapple AL, Pollack M. Art after stroke: The qualitative experience of community dwelling stroke survivors in a group art programme. Disabil Rehabil 2011;33:2346-55.

47. Obembe A, Mapayi B, Johnson O, Agunbiade T, Pt BM, Emechete A. Community reintegration in stroke survivors: Relationship with motor function and depression. Hong Kong Physiother J 2013;31:69-74.

48. Block VA, Pitsch E, Tahir P, Cree BA, Allen DD, Gelfand JM, et al. Remote physical activity monitoring in neurological disease: A Systematic review. PLoS One 2016;11:e0154335.

49. Flöel A, Werner C, Grittner U, Hesse S, Jöbges M, Knauss J, et al. Physical fitness training in subacute stroke (PHYS-STROKE) - study protocol for a randomised controlled trial. Trials 2014;15:45.

50. Bonner NS, O'Halloran PD, Bernhardt J, Cumming TB. Developing the stroke exercise preference inventory (SEPI). PLoS One 2016;11:e0164120

51. Barak S, Hutzler Y, Dubnov-Razi G. Physical exercise after stroke: Effects, recommendations and barriers. Harefuah 2016;155:378$83,384$.

52. Plow M, Moore SM, Kirwan JP, Frost F, Katzan I, Jaeger S, et al. Randomized controlled pilot study of a systemCHANGETM weight management intervention in stroke survivors: Rationale and protocol. Trials 2013;14:130.

53. Prathikanti S, Rivera R, Cochran A, Tungol JG, Fayazmanesh N, Weinmann E, et al. Treating major depression with yoga: A prospective, randomized, controlled pilot trial. PLoS One 2017;12:e0173869.

54. Chan W, Immink MA, Hillier S. Yoga and exercise for symptoms of depression and anxiety in people with poststroke disability: A randomized, controlled pilot trial. Altern Ther Health Med 2012;18:34-43.

55. Kawakita K, Okada K. Acupuncture therapy: Mechanism of action, efficacy, and safety: A potential intervention for psychogenic disorders? Biopsychosoc Med 2014;8:4

56. Man SC, Hung BH, Ng RM, Yu XC, Cheung H, Fung MP, et al. A pilot controlled trial of a combination of dense cranial electroacupuncture stimulation and body acupuncture for post-stroke depression. BMC Complement Altern Med 2014;14:255

57. Zhang GC, Fu WB, Xu NG, Liu JH, Zhu XP, Liang ZH, et al. Meta analysis of the curative effect of acupuncture on post-stroke depression. J Tradit Chin Med 2012;32:6-11.

58. Menghan L, Bo Z, Zhihong M, Tao S, Yuhui H, Hong Z, et al. Effect of Tiao shen Kai qiao acupuncture in the treatment of ischemic post-stroke depression: A randomized controlled trial. J Tradit Chin
Med 2017;37:171-8

59. Harmandayan M, Romanowicz M, Sola C. Successful use of ECT in post-stroke depression. Gen Hosp Psychiatry 2012;34:102.e5-6.

60. Shen X, Liu M, Cheng Y, Jia C, Pan X, Gou Q, et al. Repetitive transcranial magnetic stimulation for the treatment of post-stroke depression: A systematic review and meta-analysis of randomized controlled clinical trials. J Affect Disord 2017;211:65-74.

61. Brunoni AR, Boggio PS, De Raedt R, Benseñor IM, Lotufo PA, Namur V, et al. Cognitive control therapy and transcranial direct current stimulation for depression: A randomized, double-blinded, controlled trial. J Affect Disord 2014;162:43-9.

62. Gu SY, Chang MC. The effects of $10-\mathrm{hz}$ repetitive transcranial magnetic stimulation on depression in chronic stroke patients. Brain Stimul 2017;10:270-4.

63. Wright F, Wu S, Chun HY, Mead G. Factors associated with post stroke anxiety: A systematic review and meta-analysis. Stroke Res Treat 2017;2017:1-7.

64. Masskulpan P, Riewthong K, Dajpratham P, Kuptniratsaikul V. Anxiety and depressive symptoms after stroke in 9 rehabilitation centers. J Med Assoc Thai 2008;91:1595-602.

65. Barker-Collo SL. Depression and anxiety 3 months post stroke: Prevalence and correlates. Arch Clin Neuropsychol 2007;22:519-31.

66. Mok E, Woo CP. The effects of slow-stroke back massage on anxiety and shoulder pain in elderly stroke patients. Complement Ther Nurs Midwifery 2004;10:209-16.

67. Golding K, Kneebone I, Fife-Schaw C. Self-help relaxation for poststroke anxiety: A randomised, controlled pilot study. Clin Rehabil 2016;30:174-80.

68. Brown RP, Gerbarg PL. Sudarshan kriya yogic breathing in the treatment of stress, anxiety, and depression. Part II - Clinical applications and guidelines. J Altern Complement Med 2005;11:711-7.

69. Caeiro L, Ferro JM, Costa J. Apathy secondary to stroke: A systematic review and meta-analysis. Cerebrovasc Dis 2013;35:23-39.

70. van Dalen JW, Moll van Charante EP, Nederkoorn PJ, van Gool WA, Richard E. Poststroke apathy. Stroke 2013;44:851-60.

71. Petrova EA, Ponevezhskaia EV, Savina MA, Skvortsova VI. Clinical features of post stroke apathy. Zh Nevrol Psikhiatr Im S S Korsakova 2012;112:15-9.

72. Tang WK, Caeiro L, Lau CG, Liang H, Mok V, Ungvari GS, et al. Apathy and suicide-related ideation 3 months after stroke: A crosssectional study. BMC Neurol 2015;15:60

73. Bingelien A, Shapiro CM, Sockalingam S, Hawa RJ. Pathological laughing and crying post-stroke. Liaison Psychiatrist Beware 2016;6:15-21

74. Rajdeep R, Andrew H. Post-stroke mania: A rare but treatable presentation. Prog Neurol Psychiatry 2014;18:24-5.

75. Chemerinski E, Robinson RG. The neuropsychiatry of stroke. Psychosomatics 2000;41:5-14

76. Teasell R. Catastrophic reaction after stroke. A case study. Am J Phys Med Rehabil 1993;72:151-3.

77. Mnif L, Sellami R, Masmoudi J. Post-stroke emotional incontinence or bipolar disorder? Neuropsychiatr Dis Treat 2016;12:1883-5.

78. Berthier ML, Kulisevsky J, Gironell A, Fernández Benitez JA. Poststroke bipolar affective disorder: Clinical subtypes, concurrent movement disorders, and anatomical correlates. J Neuropsychiatry Clin Neurosci 1996;8:160-7.

79. Vasudev A, Thomas A. "Bipolar disorder" in the elderly: What's in a name? Maturitas 2010;66:231-5.

80. Srivastava S, Agarwal MP, Gautam A. Post stroke psychosis following lesions in basal ganglion. J Clin Diagn Res 2017;11:VD01-2.

81. McMurtray A, Tseng B, Diaz N, Chung J, Mehta B, Saito E, et al. Acute psychosis associated with subcortical stroke: Comparison n basal ganglia and mid-brain lesions. Case Rep Neurol Med 2014;2014:428425.

82. Bielawski M, Bondurant $H$. Psychosis following a stroke to the cerebellum and midbrain: A case report. Cerebellum Ataxias 2015;2:17.

83. Vurumadla S, Rakshith V, Murari C, Venkateshwarlu K. A study on symptoms, risk factors and prescribing pattern of drugs used in stroke patients. Int J Pharm Pharm Sci 2014;7:421-6.

84. Spurthi T, Rani KR, Navya Y, Swathi D, Kumar PR. Acute post complications in stroke patients visiting a tertiary teaching hospital. Int J Pharm Pharm 2018;10:95-7. 